\title{
Pengaruh Total Penduduk Dan Produk Domestik Regional Bruto Terhadap Pendapatan Asli Daerah Kabupaten Simeulue
}

\author{
Hijri Juliansyah ${ }^{* a}$, Sulkadria ${ }^{* b}$ \\ * Fakultas Ekonomi dan Bisnis Universitas Malikussaleh \\ a Corresponding author:hijri.juliansyah@gmail.com \\ b sul.kadria@yahoo.co.id
}

ARTICLE INFORMATION ABSTRACT

Keywords:

Population, GRDP, Own-

source Revenue.
The purpose of this study is to determine the effect of Population and Gross Regional Domestic Product to the Own-source revenue of Simeulue Regency. In this study, the data used are secondary data from 2007 to 2016. The method of data analysis used is multiple linear regression method. The results show that population does not affect Own-source Revenue while the Gross Regional Domestic Product influences positively to Own-source Revenue in Simeulue Regency for the period of analysis 2007-2016.

\section{PENDAHULUAN}

Pendapatan Asli Daerah (PAD) harus ditingkatkan pertumbuhannya secara cepat dan tepat. Karena, PAD merupakan suatu sumber penerimaan asli daerah yang berasal dari daerah itu sendiri. Dengan meningkatnya total dan kontribusi PAD Kabupaten/kota maka pemerintah daerah tidak lagi bergantung pada pemerintah pusat sehingga daerah yang bersangkutan dapat mandiri. PAD sangat diperlukan dalam pembangunan suatau daerah sehingga sangat tertarik untuk dikaji lebih dalam karena pertumbuhannya akan selalu mengikuti pola hidup penduduk daerah itu.

Pembangunan daerah yang sangat diinginkan adalah pembangunan yang

dibiayai dengan dana yang berasal dari daerah itu sendiri. Sumber dana daerah salah satunya adalah Pendapatan Asli Daerah (PAD). Pesatnya pembangunan di daerah mengharuskan daerah memperbaiki semua aspek yang mendukung pelaksanaan pembangunan. Salah satu aspek yang perlu diperbaiki terus ditingkatkan adalah dari aspek keuangan (fiskal). Keuangan sebagai unsur penting dalam mendukung kegiatan pembangunan harus terus dijaga dan ditingkatkan ketersediaannya. Ketersediaan keuangan sebagai sumber pembiayaan akan mempercepat proses kegiatan dan pencapaian tujuan pembangunan yang telah ditetapkan atau direncanakan. Semakin baik atau besar keuangan daerah, maka akan semakin stabil pula kedudukan pemerintah, semakin efektif dalam memberikan pelayanan dalam pembangunan dan dijadikan sebagai indikator secara nyata atas kemampuan daerah dalam melaksanakan otonomi (Rosmeli, 2010:57).

Berdasarkan penelitian terdahulu yang dilakukan oleh Nabila (2017), meneliti dengan judul: Pengaruh Jumlah Penduduk, PDRB, dan Kontribusi Pajak Daerah Terhadap PAD (Studi Kasus: Kabupaten/Kota di Provinsi Yogyakarta Tahun 2005 - 2015). Perbedaan dengan penelitian sebelumnya adalah daerah penelitiannya serta penelitian ini tidak menggunakan kontribusi pajak. Sedangkan penelitian terdahulu menggunakan kontribusi pajak. Kesamaan dengan penelitian sebelumnya adalah sama - sama menggunakan variabel PDRB dan PAD.

Perkembanagan PAD Kabupaten Simeulue dari tahun 2007-2016 adalah sebagai berikut: 


\section{Tabel 1}

Perkembangan Total Penduduk, PDRB dan Total PAD Kabupaten Simeulue Periode 2007-2016

\begin{tabular}{|c|c|c|c|c|c|c|}
\hline $\begin{array}{c}\text { Ta } \\
\text { hu } \\
\text { n }\end{array}$ & $\begin{array}{c}\text { Total } \\
\text { Pendud } \\
\text { uk } \\
\text { (Jiwa) }\end{array}$ & $\begin{array}{c}\text { Pertumb } \\
\text { uhan } \\
\text { Pendudu } \\
\text { k(\%) }\end{array}$ & $\begin{array}{c}\text { PDRB } \\
\text { (Juta } \\
\text { upiah) }\end{array}$ & $\begin{array}{c}\text { Pertu } \\
\text { mbuh } \\
\text { an } \\
\text { PDRB } \\
(\%)\end{array}$ & $\begin{array}{c}\text { PAD } \\
\text { (Juta } \\
\text { Rupiah } \\
\text { ) }\end{array}$ & $\begin{array}{c}\text { Pertumbu } \\
\text { han } \\
\operatorname{PAD}(\%)\end{array}$ \\
\hline $\begin{array}{c}200 \\
7\end{array}$ & 83,961 & - & $\begin{array}{c}213.02 \\
7,66\end{array}$ & - & $\begin{array}{c}3.625 .1 \\
05,93\end{array}$ & - \\
\hline $\begin{array}{c}200 \\
8\end{array}$ & 84,005 & 0,05 & $\begin{array}{c}231.68 \\
2,19\end{array}$ & 8,76 & $\begin{array}{c}8.120 .7 \\
35,83\end{array}$ & 1,24 \\
\hline $\begin{array}{c}200 \\
9 \\
\end{array}$ & 87,143 & 3,74 & $\begin{array}{c}243.70 \\
6,02 \\
\end{array}$ & 5,19 & $\begin{array}{l}10.586 . \\
952,00\end{array}$ & 30,37 \\
\hline $\begin{array}{c}201 \\
0 \\
\end{array}$ & 81,113 & 6,92 & $\begin{array}{c}260.61 \\
4.69 \\
\end{array}$ & 6,94 & $\begin{array}{c}8.107 .9 \\
24,04 \\
\end{array}$ & $-23,42$ \\
\hline $\begin{array}{c}201 \\
1 \\
\end{array}$ & 83,006 & 2,33 & $\begin{array}{c}271.24 \\
8,14 \\
\end{array}$ & 4,08 & $\begin{array}{c}7.231 .0 \\
84,03 \\
\end{array}$ & $-10,81$ \\
\hline $\begin{array}{c}201 \\
2 \\
\end{array}$ & 84,722 & 2,07 & $\begin{array}{c}285.25 \\
3,04 \\
\end{array}$ & 5,16 & $\begin{array}{l}14.790 . \\
455,42 \\
\end{array}$ & 104,54 \\
\hline $\begin{array}{c}201 \\
3 \\
\end{array}$ & 86,206 & 1,75 & $\begin{array}{c}298.64 \\
1,76 \\
\end{array}$ & 4,69 & $\begin{array}{l}17.478 . \\
691,00 \\
\end{array}$ & 18,18 \\
\hline $\begin{array}{c}201 \\
4\end{array}$ & 87,598 & 1,61 & $\begin{array}{c}311.58 \\
6,02\end{array}$ & 4,33 & $\begin{array}{l}17.856 . \\
829,04\end{array}$ & 2,16 \\
\hline $\begin{array}{c}201 \\
5\end{array}$ & 89,117 & 1,73 & $\begin{array}{c}325.51 \\
3,82\end{array}$ & 4,47 & $\begin{array}{l}18.234 . \\
967,08\end{array}$ & 2,12 \\
\hline $\begin{array}{c}201 \\
6\end{array}$ & 90,291 & 1,32 & $\begin{array}{c}340.80 \\
2,39\end{array}$ & 4,70 & $\begin{array}{r}18.613 . \\
105,12\end{array}$ & 2,07 \\
\hline
\end{tabular}

Sumber :kantor BPKAD kab. Simeulue (2017)

Berdasarkan Tabel 1 terlihat bahwa PAD Kabupaten Simeulue berfluktuasi dari tahun ketahun. Dari tahun 2007-2009 peningkatan. Selanjutnya di tahun 2010-2011 penurunan. Kemudian di tahun 2013 hingga 2016 mengalami peningkatan kembali walaupun pertumbuhannya tidak begitu besar. Pertumbuhan PAD tertinggi dicapai di tahun 2012 sebesar 104,54\%. Sedangkan angka pertumbuhan yang terendah adalah terjadi di tahun 2010 sebesar $-23,42 \%$. PAD dapat dipengaruhi oleh beberapa faktor antara lain total penduduk dan Produk Domestik Regional Bruto (PDRB).

Berdasarkan data di atas terdapat masalah yang terjadi yaitu disaat total penduduk di tahun 2010 menurun sedangkan PAD di tahun yang sama juga mengalami penurunan. Tetapi di tahun 2011 total penduduk meningkat sedangkan PAD di tahun tersebut justru tetap.

Dapat disimpulkan bahwa berdasarkan data tersebut maka terdapat fenomena-fenomena yaitu disaat PDRB meningkatan di tahun 2011 sedangkan PAD di tahun tersebut menurun, seharusnya PAD juga mengalami peningkatan. Maka hal tersebut tidak sesuai teori yang dikemukakan.

Berdasrkan latar belakang diatas maka peneliti tertarik untuk menulis penelitian yang berjudul: pengaruh total penduduk dan PDRB terhadap PAD di Kabupaten Simeulue.

Dimana tujuan penelitian ini adalah untuk mengetahui besar pengaruh Total Penduduk dan PDRB terhadap PAD Kabupaten Simeulue

\section{TINJAUAN TEORITIS Pendapatan Asli Daerah (PAD)}

Tujuan pembangunan daerah adalah agar tercapainya kesejahteraan masyarakat. Sebagai konsekuensi dari otonomi daerah, pemerintah daerah membutuhkan dana agar dapat membiayai pembangunan daerah. Pendapatan daerah merupakan salah satu yang bersumber dari PAD. Menurut (Nabila, 2017:1) PAD adalah penerimaan yang diperoleh daerah dari sumber-sumber dalam wilayahnya sendiri yang dipungut berdasarkan peraturan daerah sesuai dengan perundangundangan yang berlaku.

PAD merupakan penerimaan daerah yang bersumber dari daerah itu sendiri yang digali oleh pemerintah daerah yang bersangkutan. PAD sangat berperan penting dalam pembangunan suatau daerah sehingga sangat tertarik untuk dikaji lebih dalam karena pertumbuhannya akan selalu mengikuti pola hidup masyarakat di daerah itu. Salah satu tujuan dibentuknya otonomi daerah yaitu agar daerah otonom tersebut dapat mempercepat pembangun daerah Kabupaten agar kesejahteraan penduduk di daerah tersebut meningkat dan agar pemerintah lebih mudah berkomunikasih secara langsung dengan rakyatnya sehingga pelayanan publik yang dilakukan pun lebih cepat. Pembangunan daerah yang sangat diinginkan adalah pembangunan yang didanai oleh daerah itu sendidri. Sumber dana tersebut disebut dengan PAD. Menurut (Rosmeli, 2010:57), semakin baik atau besar keuangan daerah, sehingga semakin stabil pula kedudukan pemerintah, semakin efektif dalam memberikan pelayanan dalam pembangunan dan dijadikan sebagai indikator secara nyata atas kemampuan daerah dalam melaksanakan otonomi.

\section{Penduduk}

Penduduk adalah orang-orang yang berada disuatu daerah/wilayah yang saling berkomunikasi satu dengan yang lain dan mengikuti aturan-aturan yang terdapat di daerah tersebut. Penduduk suatu 
daerah/wilayah tidak sama kepadatannya dengan daerah/wilayah yang lain. Biasanya untuk menghitung kepadatan penduduk disuatu daerah/wilayah adalah dengan membagi total penduduk dengan luas area dimana penduduk itu tinggal.

Total penduduk merupakan salah satu faktor yang mempengaruhi PAD. Apabila suatu daerah memiliki penduduk yang banyak maka proses pembangunan daerah yang bersangkutan dapat semakin cepat terlaksana dan apabila suatu daerah memiliki penduduk yang sedikit maka pembangunan di daerah itu akan semakin lambat untuk dilaksanakan. Oleh sebab itu total penduduk berhubungan positif dengan PAD. Intinya adalah apabilah total penduduk disebuah daerah meningkat maka akan meningkatkan PAD tersebut. Begitu juga sebaliknya. Karena yang mengeluarkan pajak adalah masyarakat.

\section{Produk Domestik Regional Bruto (PDRB)}

Selain total penduduk yang dapat mempengaruhi PAD terdapat faktor lain yang sangat berperan penting yaitu PDRB. Faktor ini merupakan salah satu tolak ukur untuk melihat pertumbuhan dan perubahan struktur ekonomi di suatu daerah. Menurut Saragih (2003 Handayani, 2008:) jika pendapatan seseorang meningkat maka meningkatkan kemampuan orang untuk membayar berbagai pungutan yang ditetapkan pemerintah.

Pertumbuhan ekonomi di sebuah negara dapat diketahui dari tingkat PDRB negara bersangkutan. Begitu juga halnya dalam mengukur kesejahteraan manyarakatnya. PDRB biasanya terbagi menjadi dua yaitu harga konstan dan harga berlaku. PDRB harga konstan berfungsi untuk melihat pertumbuhan perekonomian suatu daeah atau negara sedangkan harga berlaku untuk melihat perubahan struktur ekonomi di daerah tersebut.

Tingkat PDRB suatu daerah berbeda dengan daerah yang lain. Hal ini disebabkan karena berbedanya potensi perekonomian dan tenaga ahli yang dimiliki derah terseebut. Apabilah suatu daerah memiliki sumber daya alam yang banyak dan daerah tersebut dapat mengelolanya dengan baik maka nilai PDRB daerah itu akan tinggi. PDRB dapat disimpulkan yaitu total nilai barang dan jasa yang diperoleh warga daerah itu sendiri dan warga daerah asing yang berada di daerah tersebut. Dengan demikian, pengertian PDRB tidak berbeda dengan PDB, hanya saja PDB merupakan perhitungan nilai barang dan jasa secara Nasional sedangkan PDRB secara regional atau wilayah. PDRB juga merupakan salah satu faktor yang sangat mempengaruhi PAD. Semakin tinggi PDRB secara langsung pajak daerah mengalami peningkatan, sehingaa penerimaan PAD juga mengalami peningkatan (Prasedyawat, 2013:57). Oleh karena itu dapat disimpulkan bahwa PDRB berhubungan positif dengan PAD.

\section{Hipotesis Penelitian}

Hipotesis adalah jawaban sementara atas objek-objek penelitian yang sedang diteliti. Adapun hipotesis dalam penelitian ini adalah sebagai berikut:

$\mathrm{Ha}_{1}=$ Diduga total penduduk berpengaruh terhadap PAD kabupaten Simeulue periode 20072016.

$\mathrm{Ha}_{2}=$ Diduga PDRB berpengaruh terhadap PAD kabupaten Simeulue periode 2007-2016.

\section{METODE PENELITIAN}

\section{Objek Dan Lokasi Penelitian}

Penelitian ini dilakukan di daerah kabupaten Simeulue dalam penelitian ini dibatasi hanya terhadap variabel total penduduk, PDRB dan PAD di kabupaten simeulue tahun 2007-2016.

\section{Sumber Data}

Penelitian ini menggunakan data skunder dari tahun 2007-2016. Untuk memperoleh informasi/data dengan cara dokumentasi yaitu peneliti mengambil data dari kantor BPS dan kantor BPKAD Kabupeten Simeulue.

\section{Metode Analisis Data}

Metode analisis data dengan menggunakan regresi linear berganda dengan persamaan sebagai berikut:

$$
\log Y=\beta 0+\beta 1 X 1+
$$

$\beta 2 \log X 2+e$

Dimana :

$$
\begin{array}{ll}
\mathrm{Y} & =\mathrm{PAD} \\
\mathrm{X} 1 & =\text { Total penduduk }
\end{array}
$$




$\begin{array}{ll}\mathrm{X} 2 & =\text { PDRB } \\ \beta 0 & =\text { Kostanta } \\ \beta 1 \& \beta 2 & =\text { Koefesien regres } \\ \log & =\text { Logaritma } \\ e & =\text { error term }\end{array}$

\section{HASIL PENELITIAN DAN} PEMBAHASAN

\section{Hasil Uji Asumsi Klasik}

\section{Uji Normalitas}

Berdasarkan hasil uji Histogram-Normality Test, terjadi atau tidaknya normalitas dapat dilihat pada Gambar sebagai berikut:
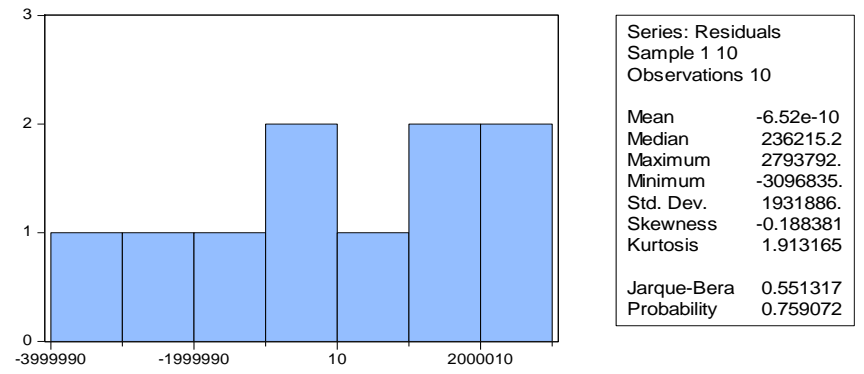

Sumber: Hasil Penelitian (Data Diolah: 2017)

\section{Gambar 1}

\section{Histogram - Normality Test}

Berdasarkan Gambar 1 dapat disimpulkan bahwa error term terdistribusi normal karena nilai probability lebih besar dari pada 0,05 atau $(0,759072>0,05)$.

\section{Uji Multikolineritas}

Terjadi atau tidaknya multikolineritas dapat dilihat pada Tabel 2 sebagai berikut:

Tabel 2

Uju Corelation Matrix

\begin{tabular}{|c|c|c|}
\hline & PDRB & PENDUDUK \\
\hline PDRB & 1 & $\begin{array}{c}0.703729070 \\
2886092\end{array}$ \\
\hline $\begin{array}{c}\text { PENDUDU } \\
\text { K }\end{array}$ & $\begin{array}{c}0.703729070 \\
2886092\end{array}$ & 1 \\
\hline
\end{tabular}

Sumber:Hasil Pelenitian (Data Diolah:2017)

Dari Tabel di atas dapat disimpulkan bahwa tidak terjadi multikolineritas pada penelitian ini karena koefesien korelasi antara variabel bebas yaitu 0,7 berarti kurang dari 0,8 atau 0,7<0,8.

\section{Uji Heteroskedasitas}

Untuk melihat terjadi atau tidaknya heteroskedasitas yaitu dengan melihat hasil regres seperti pada Tabel 4.2 sebagai berikut:
Tabel 3

White Heteroskedasticity Test

0.427

F-statistic 497 Prob. F(5,4) 0.8118

Obs*R- 3.482 Prob. Chi-

\begin{tabular}{llll} 
squared & 675 & Square(5) & 0.6260 \\
\hline
\end{tabular}

Sumber: Hasil Penelitian (Data Diolah:2017)

Dari Tabel diatas dapat disimpulkan bahwa nilai Obs*R-squarednya sebesar 0,6260 berarti PValue lebih besar dari $\alpha=5 \%(0,6>0,05)$ maka tidak terjadi heteroskedasitas dalam penelitian ini.

\section{Uji Autokorelasi}

Berdasarkan hasil regres maka terjadi atau tidaknya yaitu sebagai berikut:

\section{Tabel 4 \\ Metode Bruesch-Godfrey (LM-Test)}

Breusch-Godfrey Serial Correlation

LM Test:

$\begin{array}{llll} & 0.89847 & & \\ \text { F-statistic } & 0 & \text { Prob. F(2,5) } & 0.4641 \\ \text { Obs*R- } & 2.64374 & \text { Prob. Chi- } & \\ \text { squared } & 8 & \text { Square(2) } & 0.2666\end{array}$

Sumber: Hasil Penelitian (Data Diolah:2017)

Dari tabel di atas maka dengan tingkat keyakinan 95\% tidak ada autokorelasi dalam data penelitian karena nilai $\mathrm{P}-\mathrm{V}$ alue lebih besar dari $\alpha=5 \%$ atau $0,2666>0,05$.

\section{Hasil Regresi Linier Berganda}

hasil regres linear berganda pada penelitian ini adalah dapat dilihat pada Tabel 5 berikut:

Tabel 5

Hasil Regresi Pengaruh Jumlah Penduduk, PDRB Terhadap PAD di Kabupaten Simeulue (Periode 2007-2016)

$$
\text { Coefficie Statist Tabe }
$$$$
\begin{array}{ccccc}
\text { Variable } & \text { nt } & \text { ic } & \text { Prob. }
\end{array}
$$

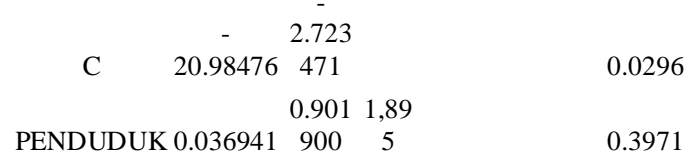




\begin{tabular}{|c|c|c|}
\hline R-squared & 0.821240 & \\
\hline $\begin{array}{l}\text { Adjusted R- } \\
\text { squared }\end{array}$ & 0.770166 & \\
\hline F-statistic & 16.07933 & $\begin{array}{c}\text { F-Tabel } \\
(4,74)\end{array}$ \\
\hline $\begin{array}{l}\text { Prob(F- } \\
\text { statistic) }\end{array}$ & 0.002415 & \\
\hline
\end{tabular}

Sumber: Hasil Penelitian (Data Diolah: 2017)

Berdasarkan Tabel 5 diatas, diperoleh hasil regresi linear berganda sebagai berikut:

$Y=-20.98476+0.036941 X 1+2.717731 X 2$

Dari persamaan diatas, dapat dijelaskan sebagai berikut:

$\beta 0:$ :Kostanta $=-20.98476$, artinya apabila variabel total penduduk dan variabel PDRB bernilai konstan, maka PAD menurun sebesar $-20,98$ persen.

$\beta 1$ :Koefesien regresi untuk X1 = 0,036941, artinya apabila variabel total penduduk mengalami perubahan 1 persen maka nilai PAD akan meningkat sebesar 0,04 persen dengan asumsi variabel PDRB tetap.

$\beta 2$ :Koefesien regresi untuk X2 $=2.717731$, artinya apabila variabel PDRB mengalami perubahan 1 persen maka nilai PAD akan meningkat sebesar 2,72 persen dengan asumsi variabel total penduduk tetap. Hal ini menunjukan bahwa PDRB berpengaruh positif terhadap PAD Kabupaten Simeulue selama periode 2007-2016.

Nilai $\mathrm{R}^{2}$ (determinasi) sebesar 0.770166, nilai tersebut menunjukan kemampuan variabel bebas dalam mempengaruhi variabel terikat adalah sebesar 0.770166, artinya adalah variabel PAD (Y) mampu dijelaskan oleh variabel total penduduk dan variabel PDRB sebesar $77 \%$ sedangkan sisanya $23 \%$ dijelaskan oleh variabel lain. Sedangkan nilai R (korelasi) sebesar 0,821240, hal tersebut menunjukan bahwa terdapat hubungan yang erat antara variabel total penduduk dan variabel PDRB dengan variabel PAD sangat kuat yaitu sebesar $82 \%$.

\section{Pembahasan}

Pengaruh Total Penduduk Terhadap PAD di Kabupaten Simeulue Periode 2007-2016

Berdasarkan hasil regresi linear berganda pada tabel 5 di atas, maka total penduduk tidak berpengaruh terhadap PAD. Menurut Badan Pusat Statistik, masyarakat Simeulue mempunyai mata pencaharian yang berumber dari bekerja pada sektor pertanian yaitu sebanyak $62,8 \%$ sedangkan sisanya adalah bergerak dibidang perdagangan, pengrajin, (PNS), buruh dan lain-lain. Oleh karena itu, salah satu penyebab total penduduk tidak berpengaruh terhadap PAD Kabupaten Simeulue adalah kurangnya pendapatan yang diperoleh masyarakat sehingga pendapatan pemerintah daerah yang bersumber dari pajak juga sedikit. Artinya adalah apabilah pendapatan masyarakat sedikit maka permintaan agregat atas barang juga sedikit, selanjutnya dengan sedikitnya permintaan atas barang maka konsumen/perusahaan akan mengurangkan total produksinya dan mengurangkan tenaga kerjanya. Hal demikian akan menimbulkan pengangguran baru akibat pemecatan tenaga kerja.

Hasil penelitian ini sesuai dengan hasil beberapa peneliti yaitu memiliki total penduduk tidak berpengraruh terhadap PAD. Penelitipeneliti tersebut seperti yang dilakukan oleh Rani, (2014:16), hasil penelitiannya menunjukan bahwa total penduduk tidak berpengaruh terhadap PAD. Hal ini disebabkan oleh Kabupaten/Kota EksKaresidenan Pekalongan sedang mengalami pengalihan sektor pertanian ke sektor industri yang terjadi sejak tahun 2010, dalam peralihan stuktur perekonomian dari pertanian ada beberapa masyakat yang tidak dapat masuk bekerja di sektor industri karena keahlian yang berbeda, dimana sektor pertania masih tradisoal, berbeda dengan industri harus mempunyai keahlian terentu untuk dapat bekerja didalamnya, perubahan stuktur ekonomi menjadikan atau terciptanya Pengangguran.

Selanjutnya penelitian yang dilakukan (Hartyanto, 2014), hasil penelitiannya juga menunjukan total penduduk tidak berpengaruh terhadap PAD. Ada beberapa indikator yang menyebabkan total penduduk tidak berpengaruh dengan PAD adalah komposisi total penduduk usia tidak produktif hampir sama dengan 
penduduk pada usia produktif yang bekerja. Usia produktif dalam konteks ini yaitu penduduk dengan usia kerja di bawah 15 tahun dan penduduk dengan kategori bukan angkatan kerja yang terdiri dari iburumah tangga, orang cacat, anak sekolah maha siswa serta pengangguran.

\section{Pengaruh PDRB Terhadap PAD di Kabupaten Simeulue Periode 2007-2016}

Secara parsial PDRB berpengaruh positif terhadap PAD. Hal tersebut sesuai dengan teori dan penelitian terdahulu yang menjadi landasan teori dalam penelitian ini seperti yang dilakukan oleh Nabila (2017), Kusuma (2014) dan Widanta (2011), bahwa PDRB berpengaruh positif terhadap PAD. Hal ini sejalan dengan pernyataan Menurut Saragih (2003 Handayani, 2008:2) Semakin tinggi pendapatan seseorang maka akan semakin tinggi pula kemampuan orang untuk membayar berbagai pungutan yang ditetapkan pemerintah.

\section{KESIMPULAN DAN SARAN Kesimpulan}

Berdasarkan rumusan masalah dan hasil penelitian mengenai pengaruh total penduduk, PDRB terhadap PAD di Kabupaten Simeulue selama periode penelitian, maSka penulis mengambil kesimpulan sebagai berikut:

Secara parsial total penduduk tidak berpengaruh terhadap PAD di Kabupaten Simeulue maka Ho diterima dan $\mathrm{H}_{1}$ ditolak, artinya adalah tidak ada hubungan antara variabel total penduduk dengan variabel PAD. Sedangkan PDRB berpengaruh positif terhadap PAD. Maka tolak Ho dan $\mathrm{H}_{1}$ diterima, artinya adalah ada pengaruh PDRB terhadap PAD selama periode penelitian yaitu sebesar $3.54 \%$. Sedangkan secara simultan total penduduk dan PDRB sama-sama mempengaruhi PAD selama periode penelitian yaitu sebesar $16.07 \%$.

Kemudian nilai $\mathrm{R}^{2}$ (determinSasi) adalah sebesar 0.770166, artinya variabel PAD mampu dijelaskan oleh variabel total penduduk dan variabel PDRB sebesar $77 \%$ sedangkan sisanya $23 \%$ dijelaskan oleh variabel lain yang tidak termasuk dalam model atau variabel yang tidak dimasukan dalam penelitian ini.
Saran

Dari hasil penelitian ini peneliti memberikan saran sebagai berikut:

1. Diharapkan bagi masyarakat agar memahami dari mana sumber PAD dan apa fungsi dan tujuannya.

2. Diharapkan kepada pemerintah daerah Kabupaten Simeulue khususnya dan setiap pemerintah daerah kabupaten agar melaksanakan hak dan kewajibannya sebagai daerah otonom yaitu dengan menggali lagi potensi-potensi sumber PAD agar dana pembangunan tidak lagi tergantung pada pemerintah pusat/bantuan perovinsi. Kemudian dalam hal pengalokasian anggaran PAD agar lebih memaksimalkan pengalokasian untuk pembangunan infrastuktur agar mempermudah kegiatan ekonomi guna meningkatkan pertumbuhan ekonomi karena apabilah pertumbuhan ekonomi meningkat maka akan meningkatkan PAD.

3. Bagi peneliti selanjutnya penulis menyarankan agar menambah variabel penelitian yang tidak di masukkan dalam penelitian ini. Dengan tujuan agar mengetahui variabel lain yang mempengaruhi terhadap PAD.

\section{DAFTAR PUSTAKA}

Bps. (2010). Pengertian Kependudukan. Https://Www.Bps.Go.Id/Subjek/View/Id/12.

Chairany, M. (2010). Analisis Total Penduduk Kecamatan Padang Bolak Pada Tahun 2012" (Tugas Akhir). Medan: Universitas Sumatera Utara.

Handayani, Sri Inda dan Evi Adriani. (2008).

Pengaruh PDRB Dan Total Penduduk Terhadap PAD Kabuparen Merangin. Jurnal Ilmiah Universitas Batang Hari Jambi Vol, 8 No. 2 Juli Tahun 2008, 8(2), 1-6.

Hartyanto, A. (2014). Studi Tentang Pertumbuhan Ekonomi, Belanja Langsung Pemerintah Daerah Dan Total Penduduk Terhadap PAD Pada Satuan Wilayah Pembangunan Gerbangkertosusila". Jurnal Ilmiah Ilmu Ekonomi. Universitas Brawijaya. Malang.

Hendriyani, N. (2017). Analisis Faktor-Faktor 
Yang Mempengaruhi PAD (Studi Kasus

Pada DPPKAD, BAPPEDA, Dan BPS

Kabupaten Boyolali Tahun 2006-2015).

Kusuma, P. A. (2014). Inflasi Dan Total Penduduk Terhadap PAD 33 Provinsi Di Indonesia.

Nabila, L. (2017). Pengaruh Total Penduduk, PDRB Dan Kontribusi Pajak Daerah Terhadap PAD (Studi Kasus : Kabupaten / Kota Di Provinsi D . I . Yogyakarta Tahun 2005 -.

Prasedyawati, L. G. (2013). Analisis Penerimaan Pajak Reklame Di Kota Semarang Tahun 1990-2011.

Prasetyo, Stevanus I. (2016). Analisis Pengaruh Total Penduduk, Tingkat Inflasi, Dan Pdrb Terhadap Penerimaan Pajak Daerah Kabupaten Dan Kota Di Provinsi Jawa Tengah (Tahun 2011-2014).

Rani, H. F. S. El. (2014). Analisis Faktor-Faktor Yang Mempengaruhi PAD (Studi Kasus Di Kabupaten/Kota Eks-Karesidenan Pekalongan Periode 2005-2014) Hening. Tugas Akhir, Universitas Muhammadiyah. Yogyakarta.

Rosmeli. (2010). Analisis PAD Provinsi Jambi Tahun 2000 - 2008. Jurnal Penelitian Universitas Jambi Seri Humaniora Volume 12, Nomor 2, Hal. 57-62, 12, 57-62.

Saputra, N. (2016). Pengaruh Pertumbuhan Penduduk Terhadap Pertumbuhan Ekonomi Di Kabupaten Nagan Raya Pada Tahun 2007-2013.

Sukirno, S. (2003). Pengantar Teori Makro Ekonomi. Jakarta: Pt.Raja Grafindo Persada.

Widanta, Gde Bhaskara Perwira Jaya Dan A.A Bagus Putu. (2011). Analisis Faktor-Faktor Yang Berpengaruh Terhadap PAD. EJurnal Ep Unud, 3 [5] :201-208, (2000), 201208. 